\title{
Inovação tecnológica e tensões curriculares: a inserção do docente no processo de criação de artefatos culturais tecnológicos
}

\author{
Alaim Souza Neto \\ UDESC, alaimsatc@yahoo.com \\ Geovana Mendonça Lunardi Mendes \\ UDESC, geolunardi@gmail.com \\ Thiago Rafael Ferreira Marques \\ SENAC/SC, thiagorafaelmarques@hotmail.com
}

Resumo

O presente artigo tem como objetivo investigar a apropriação pedagógica de artefatos culturais tecnológicos desenvolvidos com a participação direta do docente no processo de criação e design destes artefatos. O trabalho tem como foco principal a discussão e compreensão de como estes artefatos se estabelecem na escola e como eles podem vir a impactar as estruturas curriculares, buscando assim problematizar e debater acerca as inovações tecnológicas e pedagógicas. São apresentados e debatidos ainda os resultados empíricos relacionados a uma experiência de design colaborativo de um jogo digital e seu uso em salas de aula do ensino fundamental de uma escola pública.

Palavras-Chave: Inovação tecnológica e pedagógica; Estruturas curriculares; Jogos educativos

\begin{abstract}
This article aims to investigate the pedagogical appropriation of technological cultural artifacts developed with the direct participation of the teachers in the creation and design process of these artifacts. The work is mainly focused on the discussion and understanding of how these artifacts are established in school and how can they impact on the curriculum frameworks, thus seeking to question and debate about the technological and pedagogical innovations. Empirical results related to an experience of collaborative design from a digital game and its use in classrooms from elementary education at a public school are presented and further discussed.
\end{abstract}

Keywords: Technological and pedagogical innovation; Curriculum frameworks; Educational Games. 


\section{Introdução}

Com o grande advento da internet de forma potencializada a partir do início desse século, percebemos em poucos anos na sociedade, o surgimento da web 1.0 passando pela web 2.0 e atingindo seu ápice na contemporaneidade com a web 3.0, alterando radicalmente as formas e sistemas de comunicação. Rapidamente, saímos da passividade frente à tela da TV nos anos 1950/1960, cruzamos a transição para a sociedade midiática nos anos 1980 e 1990 e nos deparamos com os anos 2000 em que as crianças nascem imersas num mundo digital. No cenário de educação a distância no Brasil surge uma tendência e perspectiva para a educação online que marca territórios e preferências. Isso pode ser observado nos dados do Censo EaD do ano de 2010, os quais mostram claramente que o modo síncrono de aprendizagem já está quase ultrapassando o modo assíncrono para utilização de artefatos tecnológicos nas instituições (ABED, 2012). Não muito diferente, é a expressividade do número de pessoas no mundo que estão conectadas às redes sociais na internet.

Nesse contexto, o contato social se desterritorializa, a expressão corporal passa a ficar ausente e limitada, e ainda, o meio online assume diversas versões, tanto na escola como fora dela. Particularmente na escola, as demandas pedagógicas se encontram também em busca de novos métodos de ensino e aprendizagem frente à geração de alunos "plugados", tentando se conectar ao mundo digital que já está disponibilizado na sociedade. Nesse sentido, vários são os autores na área de educação que já nos alertaram para a inserção de tecnologias digitais nos processos educativos como uma necessidade cada vez mais exigida (JONHSON, 2012; FANTIN, 2006).

Os desdobramentos desse mundo digital na escola desestabilizam as relações entre professores e educandos com o tempo, o espaço e, principalmente, os saberes pedagógicos, propriamente os conteúdos curriculares, prescritos na lógica tradicional da escola como fonte única de acesso ao conhecimento poderoso de que Young (2007) nos fala. Como afirma Dussel (2011) "estamos diante de mudanças de natureza profunda nas verdades e estruturas que sustentam as práticas escolares”. Utilizar os novos artefatos em todas as suas potencialidades significa questionar o modelo comunicacional presente em sala de aula, os regimes de verdade por meio dos quais a escola organiza e distribui o conhecimento produzido e também as formas de produção de conhecimentos, entre outras questões relevantes.

Para aqueles que se encontram envolvidos com as pesquisas que relacionam educação a distância ou presencial, comunicação e tecnologias digitais, muitos são os termos que permeiam as investigações nessas áreas, entre eles: MOOCs, tablets, apps, SEO, NTDICs, MUVs, MMPORGs, ipad, ipod, enfim, itudo, itodos... Contudo, será que todos os interessados com essas discussões no âmbito da academia estão familiarizados com as suas origens, suas implicações, suas possibilidades e limitações e suas representações na sociedade, particularmente na educação? De fato, esses termos implicam pesquisas investigativas a fim de compreender os impactos desses artefatos culturais na sociedade e na educação. Esclarecer essa e, outras questões, são demandas necessárias na atualidade no que tange às pesquisas em educação, comunicação e tecnologia.

Apresentamos este artigo, dada a sua relevância ao momento vivido no contexto educacional brasileiro, no qual se encontra em expansão para a inserção de novos artefatos culturais na educação em diferentes níveis, bem como as ofertas de ensino na modalidade "a distância”. Este fato tem exigido se repensar os currículos escolares a fim 
de que possamos propiciar uma educação para esse tempo histórico e social, formando homens e mulheres de seu tempo, como propunha Freire (1996), o que significa na atualidade também educar para emancipação digital cidadã. Em outras palavras, Lunardi Mendes, Correa e Borges (2009) apud Sancho (2011), afirmam que parece que estamos diante de uma espécie de "cavalo de tróia”, ou seja, a crença que somente a inserção das tecnologias no contexto escolar provocará mudanças nas práticas e no currículo.

Delimitando melhor o objeto deste artigo, esclarecemos que nossa proposta é investigar a apropriação pedagógica de artefatos culturais tecnológicos desenvolvidos com a participação direta do docente no processo de criação e design destes artefatos. $\mathrm{O}$ trabalho tem como foco principal a discussão e compreensão de como estes artefatos se estabelecem na escola e como eles podem vir a impactar as estruturas curriculares, buscando assim problematizar e debater acerca as inovações tecnológicas e pedagógicas.

Pesquisas realizadas, principalmente nos últimos 10 anos (FAGUNDES et al, 2005; GVIRTZ et al, 2007), apontam que há falta de orientações sobre o que fazer com os computadores que chegam às escolas. Nesses estudos e tantos outros, fica claro que a evolução das tecnologias tem um importante papel na globalização, provocando mudanças nos modos de ser e estar no mundo, reconfigurando as relações comunicacionais e fazendo surgir novas ordens sociais, denominadas de: sociedade tecnológica, sociedade em rede, sociedade da informação, sociedade do conhecimento, sociedade cognitiva, sociedade digital e muitas outras ainda.

Neste contexto, buscou-se descrever os resultados de um projeto intitulado "Design Colaborativo de Jogos Educacionais: Uma proposta de inserção do docente no processo de criação de artefatos culturais tecnológicos”. A questão central para nós não será mais a adesão ou não às novas tecnologias nos processos educativos, e muito menos, a promoção ou não ao acesso aos dispositivos tecnológicos disponíveis. A problemática deste artigo se concentra na discussão e compreensão de como esses artefatos tecnológicos se estabelecem na escola a partir da inserção direta do docente no processo de design e criação de artefatos tecnológicos, e como os resultados desta interação entre docente e tecnologia impacta no cotidiano escolar e nas estruturas curriculares da escola e da sala de aula.

Ou seja, a intenção é tornar público como um artefato cultural tecnológico, na forma de um jogo educativo criado pelos docentes foram recebidos pelos educandos durante as práticas escolares, atentando para elementos didático-pedagógicos que revelam uma possibilidade de termos no contexto escolar, inovações pedagógicas curriculares durante os processos de ensino e aprendizagem que se sobrepõem às meras inovações tecnológicas, bem como descortinar práticas pedagógicas da escola que possam ser utilizadas, tendo como base novas concepções de educação, currículo e inovação. Não a inovação que procura enfatizar a questão das experiências dos alunos, bem como seus interesses e contextos, mas sim a inovação que privilegie o conhecimento científico (YOUNG, 2010).

Entendemos que o uso dos artefatos culturais tecnológicos podem potencializar o processo de ensino e aprendizagem como transformadores e produtores de novos conhecimentos com vistas à inclusão digital, pois esses artefatos podem estruturar o pensamento, o modo de ser, estar e de se relacionar no e com o mundo. Nesse sentido, em relação às mídias e tecnologias, elas podem ser utilizadas como estruturantes para novos currículos escolares (ALMEIDA, 2013).

Para melhor compreender a inserção do docente no processo de desenvolvimento tecnológico, seus resultados e seus impactos em novas formas de pensar o currículo escolar, também apresentamos a descrição do método de construção 
do jogo por parte dos docentes, e o feedback da aplicação deste jogo por parte dos alunos.

\section{Currículo e Tecnologias}

Na contemporaneidade, de diferentes formas, vários são os países que tecnologicamente avançados ou em desenvolvimento, lançaram projetos e políticas de mudanças tecnológicas para as práticas escolares. Conforme Sancho (2011), tivemos primeiramente a informática educativa, depois as TIC aplicadas à educação e atualmente projetos como e-learning, m-learning e u-learning. Tais projetos e políticas demandam melhorias nos processos de ensino e aprendizagem dos alunos, bem como reformas nas formas de organização escolar. São posturas que os responsáveis pelas políticas públicas precisam tomar ciência, pois só a presença de tecnologias nas escolas não garante resultados satisfatórios na melhoria da aprendizagem e no desenvolvimento do currículo (SOSSAI et al, 2009; ALMEIDA, 2008; VALENTE et al, 1997).

No que se refere à organização escolar, recorremos a Almeida (2013), a qual nos apresenta uma primeira compreensão para o conceito de currículo que se sustenta na compreensão da organização e da construção do conhecimento na ação de aprender. Para a autora, “[...] o currículo será construído no próprio desenvolvimento da formação, se orientará pelas pesquisas e para a pesquisa, o que valoriza a postura problematizadora por parte de formadores e de formados” (ALMEIDA, 2013).

É nossa intenção, problematizar essa e outras concepções de currículo que possam se relacionar ao uso das tecnologias no espaço escolar. Contudo, para compreender a relação entre currículo e tecnologias e suas relações na sala de aula, precisamos primeiramente compreender a concepção de currículo, tomando como referência o seu ambiente de privilégio: o contexto escolar. Para isso, buscamos em Young (2007) uma resposta para a pergunta: “para que servem as escolas?”. Para o autor, essa questão significa perguntar “[...] como e por que as escolas emergiram historicamente, em tempos e sociedades diferentes, como instituições específicas, com o propósito específico de capacitar alunos a adquirir conhecimento não disponível em casa ou no seu cotidiano" (YOUNG, 2007). Para o autor, o currículo precisa considerar o conhecimento local e cotidiano que os alunos trazem à escola, contudo esse conhecimento não deverá ser a referência para a construção do currículo. Ele também defende que a educação na sociedade do conhecimento precisa ter um currículo organizado a partir das necessidades de aprendizagem, ou seja, um currículo que privilegie o conhecimento e diverso do modelo tradicional de currículo para submissão.

Acrescenta, ainda, que o conhecimento local é estruturado de forma a relacionar-se com o particular e não poderá ser a base dos princípios generalizáveis. Essa seria a razão pela qual todos os países têm escolas, e por isso, a necessidade de se diferenciar o conhecimento escolar e não-escolar. Para Young (2010), fica claro que os educandos não vão à escola para aprender sobre suas experiências, mas para se apropriar de conhecimentos gerados pelas pesquisas e pela comunidade científica. Ele ainda destaca que esse tipo de conhecimento é que dá sentido à escola e confiabilidade ao currículo, visto que a escola é um lugar em que se dá a transmissão do conhecimento e do poder e o mundo aparece como objeto de reflexão. Segundo Lunardi Mendes (2011),

No fundo, a possibilidade de dispor de um enorme arquivo de cultura, como nunca antes disponível, e também a possibilidade de participar de processos de construção coletiva de conhecimento, evidenciam a necessidade curricular de discutir a própria validade do 
conhecimento escolar que está sendo ensinado e torna urgente o trabalho da escola com o que Young (2007) chama de conhecimento poderoso, ou seja, um conhecimento de qualidade científica muitas vezes inacessível em outros ambientes por crianças que vivem em condições sociais desfavorecidas.

Feita a reflexão sobre o papel da escola, resta ao professor compreender a sua função enquanto educador no desenvolvimento do currículo, refletindo continuamente sobre várias questões norteadoras da sua prática: "o que, como, para quê, para quem, a favor de quem" se estrutura o processo de ensino e aprendizagem de modo a conduzir os educandos à “reconstrução do saber ensinado” (FREIRE, 1996).

Neste artigo, cabe-nos ainda desmistificar algumas concepções de currículo que rondam o contexto educacional. Nessa empreitada, o conceito de currículo nos exige uma tomada de decisão frente aos vários discursos e visões sobre o assunto dada a polissemia do termo. Em primeira consulta ao Dicionário Houaiss, o termo currículo é uma expressão que tem sua origem no latim curriculum, que significa corrida, carreira, lugar onde se corre, campo”, liça”, hipódromo e picadeiro, e ainda, do verbo em latim currere, que significa correr”, curso. De saída, já percebemos de forma ingênua que a concepção de currículo diz respeito a um percurso ou trajetória de um curso, algo muito além das listas de conteúdos, temas de estudo ou unidades de ensino, extrapolando em muito as prescrições curriculares e envolvendo todo o lugar e o tempo em que ele se desenvolve (ALMEIDA et al., 2011).

Lexicamente, Pacheco (1996) contrapõe duas noções implícitas de na concepção de currículo: "uma sequência ordenada, outra de noção de totalidade de estudos [...]. O currículo é uma prática pedagógica que resulta da interação e confluência de várias estruturas na base das quais existem interesses concretos e responsabilidades compartilhadas”. Michael Apple (1994) acrescenta que o currículo ainda precisa se caracterizar como um processo de reconstrução em um ambiente de representações técnicas, estéticas, éticas, políticas e ideológicas, segundo uma "tradição seletiva" do que é considerado “conhecimento legítimo". Para dar mais peso a essa concepção de currículo, adotaremos conceitos do campo curricular de três grandes teóricos: Ivor Goodson, Antônio Flávio Moreira e Michael Young.

Primeiramente, para Goodson (2006), o conceito de currículo é compreendido como uma construção social que se desenvolve na interação dialógica entre escola, vida, conhecimento e cultura, produzindo os mais diferentes percursos. Dessa forma, o currículo acaba por integrar os conteúdos da cultura selecionados criteriosamente de acordo com determinadas intenções para uso nos processos de ensino e aprendizagem, com as múltiplas concepções, valores, ideologias, experiências, tecnologias e estratégias sendo mobilizadas para a realização do contexto pedagógico.

Assim, o currículo não pode ser compreendido como a aplicação e transferência do conteúdo prescrito em documentos referenciados pelas mais diversas instituições, livros didáticos, planos de ação, sistemas de ensino e portais educativos, posteriormente sendo repassado aos educandos no contexto da sala de aula. Pelo contrário, ele precisa se desenvolver na reconstrução desse conteúdo prescrito nos processos de representação de significados e negociação de sentidos que ocorrem, primeiramente, no momento em que os professores planejam a condução de suas disciplinas, considerando as características do seu contexto de sala de aula, as potencialidades e necessidades dos seus educandos, bem como suas preferências e sua forma de conduzir a prática pedagógica. Assim, teremos um currículo ressignificado no momento da ação pedagógica (ALMEIDA et al., 2011). 
Em seguida, para Moreira e outros (1994), o desenvolvimento curricular não pode ser restrito aos conteúdos prescritos em grades que se estabelecem pelas disciplinas curriculares, e muito menos aos conhecimentos que relacionam as experiências e conhecimentos dos educandos sobre seu cotidiano. Concordamos com os autores, por achar fundamental diferenciar um currículo que parte da experiência e conhecimento do senso comum daquele que se constrói em torno da experiência e da aplicação do conhecimento à realidade cotidiana do educando. Afirmamos isso a partir da ideia de "[...] que o conhecimento formal traz outras dimensões ao desenvolvimento humano, além do „uso prático” e somos defensores da ideia de uma metodologia que parte da "experiência cultural do aluno como caminho para ampliação da experiência humana na escola” (MOREIRA et al, 1994).

Essa concepção não nega a disciplina e o conteúdo curricular, contudo necessita identificar a estrutura lógica de cada área do conhecimento, revendo a concepção de disciplina e sua função na escolarização de modo a transformá-la em algo flexível que inclua o conhecimento do senso comum que o educando traz de sua realidade. Nesse processo, o professor precisa dialogar com os educandos, despertando-lhes a curiosidade sobre os grandes eventos do mundo, problematizando sua realidade e propondo atividades em que explicitem o que já sabem sobre seu mundo, mas buscando novas informações que possam transportá-los do estágio do conhecimento do senso comum para um novo patamar do conhecimento, ampliado de possibilidades para compreender o seu mundo e de formalizar o conhecimento científico (ALMEIDA et al., 2011).

Nessa esteira de reflexões, resta-nos ainda acrescentar as contribuições de Young (2010), as quais problematizam as inovações pedagógicas e curriculares, afirmando que temos um longo caminho pela frente a ser enfrentado no contexto educacional brasileiro. Na verdade, ficam nas palavras de Young (2010) a necessidade contínua de uma prática sem fim e sem soluções absolutas e definitivas. Há que se estabelecer um processo dialético de pesquisa que sempre problematize como o currículo do futuro se estabelecerá no contexto educacional. Enfim, segundo Young (2010):

\begin{abstract}
A idéia de um "currículo do futuro" continua a ser isso mesmo - uma tendência e uma idéia que dificilmente encontramos em qualquer forma institucional. É inquestionável que ela ainda tem um longo caminho a percorrer no que respeita ao estabelecimento de uma base de confiança que demonstre que se tratará de uma maneira de promover aprendizagens de alta qualidade.
\end{abstract}

A partir da concepção que relaciona os teóricos que trouxemos à baila neste artigo, poderemos contemplar um currículo que vê nas tecnologias a possibilidade de deixar de ser centrado em conteúdos prescritos associados ao ensino por meio de métodos instrucionistas e baseado na distribuição de materiais didáticos em que pesem a digitalização e o uso do software para valorizar a lógica disciplinar. Assim, conforme Almeida e Valente (2011), podemos ver nas tecnologias uma potencialização da comunicação multidirecional, das representações do conhecimento por meio de distintas linguagens e do desenvolvimento de produções colaborativas com educandos localizados nos mais diversos lugares, tempos e contextos, superando a abordagem ancorada em princípios de racionalização e divisão do trabalho propostos por "Tyler" e "Bobbit" (KLIEBARD, 2011; KLIEBARD, 2011) em prol de uma abordagem dialógica, polifônica, construtiva e histórico-social.

Metodologia 
A utilização de jogos eletrônicos nos processos de aprendizagem tem sua importância comprovada no aumento da efetividade educacional e do envolvimento do aluno com a matéria em questão (PAPASTERGIOU, 2009).

Apesar deste panorama, os jogos ainda estão distantes do contexto da sala de aula. O desenvolvimento de jogos educativos se dá por empresas ou iniciativas que não possuem contato direto com o público que se espera atingir, criando uma inconsistência entre aquilo que é efetivamente abordado no contexto da sala de aula e aquilo que é oferecido pelos jogos eletrônicos. Os repositórios de jogos educativos não levam em conta as particularidades, culturas, formas de aprendizado e dinâmicas únicas de cada sala de aula.

A motivação científica desta pesquisa está em comunicar a primeira experiência prática de imersão de professores no desenvolvimento e criação de artefatos culturais tecnológicos - na forma de jogos digitais - aplicados como dispositivos pedagógicos levando em consideração os aspectos cognitivos e pedagógicos do processo de ensino e aprendizagem, como mais uma das muitas tentativas de se pensar possíveis alterações nas estruturas curriculares da educação formal como também problematizar o processo de ensino e aprendizagem.

O objetivo geral foi compreender quais são as primeiras contribuições ou limitações destas novas possibilidades criadas diretamente pelos docentes para o processo de ensino e aprendizagem, fomentando uma discussão acerca das estruturas de currículo e a inserção do docente na prática pedagógica.

Em reuniões entre uma equipe de desenvolvimento de tecnologias digitais e docentes de uma escola pública federal de Florianópolis-SC, foram definidas as estruturas básicas deste jogo digital, baseando-se nos conceitos de design de games disponíveis na literatura (SCHUYTEMA, 2008; SALEN e ZIMMERMAN, 2012).

Dessa forma, os docentes optaram por construir um jogo focado no conteúdo da $4^{\mathrm{a}}$ série do ensino fundamental, especificamente, para a disciplina de história. Com base nos materiais didáticos, livros, avaliações e conhecimentos dos docentes, delineou-se o jogo Desbravando Floripa. Toda a estrutura do jogo, incluindo conceito, design gráfico, narrativa, gameplay, conteúdo, revisão e aplicação, foram construídos com base em reuniões e decisões da equipe de professores da escola.

Por fim, a versão final do jogo desenvolvido propôs como dinâmica central a adivinhação, em que o jogador é apresentado a um tema misterioso (não revelado), e é convidado a utilizar seu conhecimento prévio no tema, e em conjunto com dicas oferecidas pelo próprio jogo, acertar qual seria o tema misterioso. Após acertar, o jogador tem acesso às informações sobre o tema, e a partir daí pode fazer uma reflexão sobre a questão central e correlacionar com o conteúdo aprendido. Todo o conteúdo e a temática do jogo foram estruturados com base nos conteúdos que foram apresentados durante o ano de 2013 para a disciplina de história, (neste caso, o conteúdo abordou a história de Florianópolis) garantindo uma grande consistência entre a prática educativa da sala de aula e a apresentação do jogo eletrônico.

Após o desenvolvimento, o jogo foi aplicado para duas turmas da $4^{\mathrm{a}}$ série do ensino fundamental, totalizando 49 educandos (90\% crianças com 10 anos de idade, e 10\% com 11 anos). Cada aplicação teve como duração 10 minutos de jogo, dentro de um intervalo de 2 dias entre cada uma delas. Todas as aplicações foram realizadas em duplas de alunos, buscando um maior senso de colaboração e cooperação. Como instrumentos de coleta de dados para obter informações acerca dos grupos participantes, utilizamos um questionário aplicado aos alunos após todos os procedimentos.

Resultados e discussão 
Os resultados da aplicação do questionário pós-aplicação podem ser vistos na Figura 1:

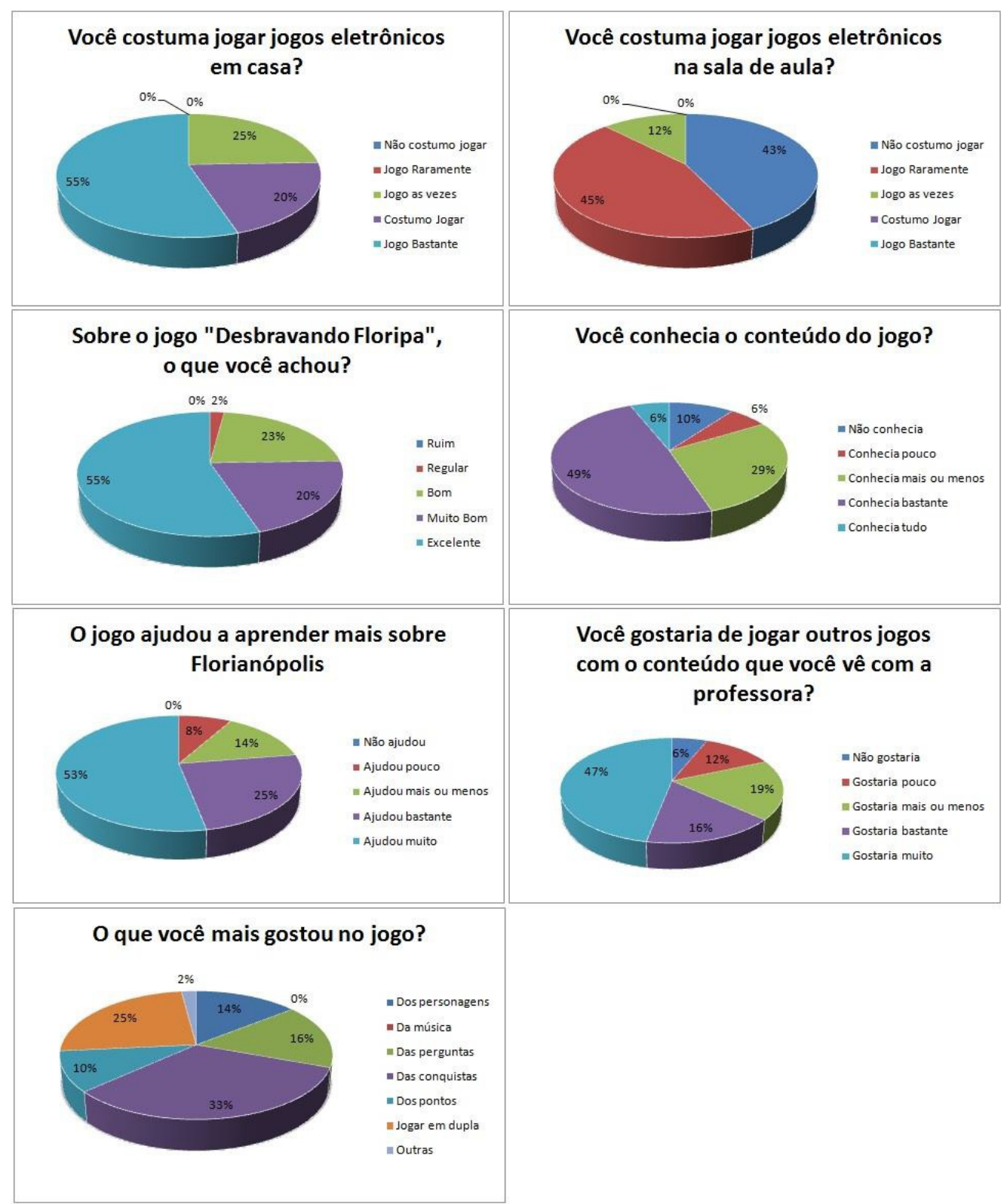

Figura 1 - Resultados da aplicação

A primeira questão que se destaca nos resultados, é a grande divergência entre o hábito dos respondentes de jogar jogos eletrônicos em casa (75\% afirmam que costumam jogar ou jogam bastante) e jogar jogos em sala de aula (88\% afirmaram que não costumam jogar ou jogam raramente). Esta divergência também pode ser observada na prática da aplicação. Os alunos tiveram reações efusivas e extremamente positivas no decorrer da experiência, em que muitos pediram aos pesquisadores mais tempo com o jogo ou mais aplicações da atividade. Uma das alunas, numa questão aberta do questionário, solicitou que o educando "falasse um pouco sobre como foi jogar”, relatou: "Foi legal porque a gente mal mexe em coisa eletrônica". Outra aluna comenta, ainda: "Foi muito legal pra sair um pouco da rotina". Os resultados estatísticos, aliados às 
observações e aos relatos dos participantes, demonstram uma clara falta de contato com artefatos tecnológicos dentro do contexto de sala de aula por parte dos educandos.

Pode-se observar, ainda, que grande parte dos respondentes teve uma reação positiva em relação ao jogo (75\% acharam o jogo Muito Bom ou Excelente). Pode-se, ainda, extrais que o jogo foi considerado útil para o processo de aprendizagem, visto que $78 \%$ afirmaram que o jogo ajudou muito ou ajudou bastante com o conteúdo sobre Florianópolis.

A facilidade de interação com os objetos se deu de forma muito natural e rápida para os alunos, pois muitos pareciam já ter tido alguma experiência ou aproximação com esse tipo de interação digital (90\% afirmaram não ter tido nenhuma dificuldade com o jogo). O mais provável talvez seja que a experiência e naturalidade com jogos digitais aliada ao conhecimento relacionado à temática apresentada em sala de aula, criou uma situação de conforto com o artefato, evitando estranhamentos e dificuldades.

\section{Considerações Finais}

Em se tratando da participação do docente no processo de design e criação de jogos digitais, esta pode representar uma alternativa potencial face às novas gerações plugadas, já que são artefatos de alta inovação tecnológica, que aliadas ao conhecimento aplicado do docente, podem se tornar artefatos culturais de práticas inovadoras, podendo contribuir com o aperfeiçoamento dos processos de ensino e aprendizagem da contemporaneidade. Porém, deve-se observar que é necessário para a sua aplicação, avançar nas discussões que tratam da estrutura tecnológica, do processo de formação de professores, e muito mais, do próprio processo de ensino e aprendizagem.

A pesquisa representa, sem dúvida, mais um avanço para a área educacional, a qual busca alternativas para a melhoria dos seus processos pedagógicos. Nas respostas escritas pelas turmas, foi observada a motivação em não simplesmente jogar, mas de buscar o conhecimento necessário para a construção do aprendizado dentro da estrutura construída pelos próprios docentes. Este resultado encoraja os pesquisadores a realizar outras pesquisas, aplicando-os nas mais diferentes áreas do conhecimento.

Essa experiência trouxe aos participantes novos olhares quanto ao uso das tecnologias digitais em sala de aula. Os relatos de professores e educandos firmam a necessidade de se investir em ambientes similares para suprir as lacunas existentes hoje em sala de aula e tornar esse acesso às tecnologias presente também no contexto educativo. Muitas foram as contribuições dos professores e educandos que deixaram explícitos suas expectativas para acessos futuros.

Em se tratando do campo curricular, a pesquisa foi feita a partir de distintos olhares e tem haver com a necessidade de recorrência de diálogos sobre a relação currículo e tecnologias na contemporaneidade. Em especial, de uma profunda reflexão sobre os saberes e fazeres no âmbito das intervenções pedagógicas em que cada uma das concepções de currículo, descritas neste artigo, procura deixar claro, é que o currículo não se restringe às concepções prescritivas em seu processo e nem mesmo quanto às aplicações que delas derivam. Antes, o seu caráter educativo solicita intervenções permanentes e aproximadas da definição do próprio homem: um ser em movimento e transformação. Nessa leitura, a busca pela superação de desigualdades, superação de injustiças sociais, releituras de conquistas efetivadas e aspirações do que ainda não se enquadra como desejado, não pode ser ignorada. A reflexão a partir de estudos sobre o currículo frente à realidade atual nos apresenta pistas sobre tais demandas e nos impulsiona às indagações que podem aprimorar algumas interfaces educacionais entre o campo do currículo e a discussão sobre a s tecnologias no contexto escolar. Certamente 
temos muito que aprender e evoluir em relação as outras pesquisas sobre a temática, mas já ficamos enobrecidos pela disponibilização da pesquisa apresentada neste artigo.

\section{Referências Bibliográficas}

ABED, “Censo EaD.BR 2010,” São Paulo: Pearson, 2012.

ALMEIDA, Maria Elizabeth Bianconcicni, “Informática e Formação de professores,” Brasília: Ministério da Educação, 2000. v. 2. Disponível em: <http://www.scribd.com/doc/26138566/Livro09Elizabeth-Almeida\#fullscreen:on>. Acesso em: 10 maio 2013.

ALMEIDA, Maria Elizabeth Bianconcini e VALENTE, José Armando, Tecnologias e currículo: trajetórias convergentes ou divergentes? São Paulo: Paulus, 2011.

ALMEIDA, Maria Elizabeth Bianconcini, "Tecnologias na educação: dos caminhos trilhados aos atuais desafios,” BOLEMA - Boletim de educação Matemática, UNESP, Rio Claro, 2008.

APPLE, Michael, Repensando ideologia e currículo. In: M. Antonio Flávio e S. Tomaz Tadeu da. (Orgs), Currículo, cultura e sociedade. São Paulo: Cortez, 1994.

DUSSEL, Inés, “VII Foro Latinoamericano de Educación: aprender y enseñar en la cultura digital”. Buenos Aires: Santillana, 2011.

FAGUNDES, Léa da Cruz e BASSO, Marcos Vinícius de Azevedo, Mídias digitais, sistemas de conceitos e aprendizagem em matemática. Revista Brasileira de Informática na Educação, vol. 13, n. 2, p. 42-52, 2005.

FANTIN, Monica, “Mídia-Educação: conceitos, experiências, diálogos Brasil-Itália,” Florianópolis: Cidade Futura, 2006.

FREIRE, Paulo, “Pedagogia da autonomia: saberes necessários à prática educativa,” 14. ed. São Paulo: Paz e Terra, 1996.

GOODSON, Ivor, As políticas de currículo e de escolarização. Abordagens históricas. Petrópolis, RJ: Vozes, 2006.

GVIRTZ, Silvina e LARRONDO, Marina, “Notas sobre la escolarización de la cultura material, Celulares y computadoras en la escuela de hoy,” Revista TEIAS: Rio de Janeiro, ano 8, n. 15-16, jan/dez. 2007.

JONHSON, Steven, “Tudo que é ruim é bom para você: como os games e a TV nos tornam mais inteligentes,” Rio de Janeiro: Zahar, 2012.

KLIEBARD, Herbert M, Burocracia e Teoria do Currículo. Currículo sem Fronteiras, v. 11, n. 2, p. 5-22, jul./dez. 2011.

KLIEBARD, Herbert M, Os Princípios de Tyler. Currículo sem Fronteiras, v. 11, n. 2, p. 23-35, jul./dez. 2011.

LUNARDI MENDES, Geovana Mendonça (Coord.), “Aulas Conectadas? Mudanças Curriculares e Aprendizagem Colaborativa entre as Escolas do Projeto UCA em Santa Catarina,” Projeto de Pesquisa Edital CNPq/Capes/SEED-MEC n. 76/2010, Florianópolis, 2011.

LUNARDI MENDES, Geovana Mendonça, CORREA, Juan Casanova e BORGES, Martha Kaschny, "Entrevista com a Professora Doutora Juana María Sancho,” Revista Linhas, Espanha, Universidade de Barcelona, p. 03-14, 2009.

MOREIRA, Antonio Flávio e SILVA, Tomaz Tadeu da (Orgs), Currículo, cultura e sociedade. São Paulo: Cortez, 1994.

PAPASTERGIOU, M. Exploring the potential of computer and video games for health and physical education: A literature review. Computers \& Education, v. 53, n. 3, p. 603-622, 2009.

SALEN, K.; ZIMMERMAN, E. Regras do jogo: fundamentos do design de jogos. São Paulo: Blucher, 2012.

SANCHO, Juana Maria, “Tecnologias digitais, formação de professores e contextos escolares: novos desafios, velhos problemas,” Entrevistafeita por: L. M. Geovana Mendonça, C. Juan Casanova e B. Martha Kaschny In: L. M. Geovana Mendonça e B. Martha Kaschny (Orgs.). Dossiê Revista Linhas: Educação, Comunicação e Tecnologia em debate. 2. ed. Florianópolis: UDESC, 2009. v. 10.

SCHUYTEMA, Paul. Design de Games: Uma abordagem prática. Cengage Learning, 2008.

YOUNG, Michael, “Conhecimento e currículo: do socioconstrutivismo ao realismo social na sociologia da educação,” Tradução de Jorge Ávila de Lima. Porto: Porto Editora, 2010.

YOUNG, Michael, "Para que servem as escolas? Educação e Sociedade,” Rio de Janeiro, vol. 28, n. 1001, p. 1279-1282, set/dez. 2007. 